\title{
Dynamic Coevolution of Capital Allocation Efficiency of New Energy Vehicle Enterprises from Financing Niche Perspective
}

\author{
Qiong Wang $\mathbb{D},{ }^{1,2}$ Cheng-xuan Geng $\mathbb{D}^{1},{ }^{1}$ and Hai-tao $E \mathbb{D}^{3}$ \\ ${ }^{1}$ College of Economics and Management, Nanjing University of Aeronautics and Astronautics, Nanjing 211106, China \\ ${ }^{2}$ Aliyun School of Big Data, Changzhou University, Changzhou 213164, China \\ ${ }^{3}$ Propaganda Department, Nanjing University of Aeronautics and Astronautics, Nanjing 211106, China
}

Correspondence should be addressed to Cheng-xuan Geng; gcxuan@nuaa.edu.cn

Received 2 January 2019; Revised 5 April 2019; Accepted 14 April 2019; Published 2 May 2019

Academic Editor: Konstantinos Karamanos

Copyright (C) 2019 Qiong Wang et al. This is an open access article distributed under the Creative Commons Attribution License, which permits unrestricted use, distribution, and reproduction in any medium, provided the original work is properly cited.

\begin{abstract}
Based on the dynamic characteristics of enterprises' competition and cooperation, this paper introduces the idea of ecology and synergy and constructs a dynamic coevolution model of financing allocation efficiency and financing niche based on improved Lotka-Volterra model. The parameters in the model are difficult to be given by the least square method and the maximum likelihood estimation method; the accelerated genetic algorithm is proposed to solve the parameters in the dynamic coevolution model, which makes the parameter estimation more accurate and reasonable. Finally, the data of new energy vehicle listed companies in China from 2009 to 2017 are given to validate the proposed model, and the dynamic process of coevolution of new energy vehicle enterprises, capital allocation efficiency, and financing niche is described. The results show that the minimum financing niche breadth of industry and market determines the location of the equilibrium point. With capital allocation efficiency as the core, adjusting the financing niche through financing market, industrial policy, enterprise development, and other factors will help to improve the coevolution balance between industrial capital allocation efficiency and financing niche and promote the coordinated development of strategic emerging industries.
\end{abstract}

\section{Introduction}

According to the theory of ecology, natural ecosystem is a dynamic equilibrium system formed by the interaction of organisms, other organisms, and their environment. Enterprise is equivalent to biology and industry is equivalent to the biology community. Financing market is the carrier of its survival and development, providing the necessary funds, information, and energy for the development and reproduction of enterprises and industries. Enterprises and industries, as well as their environment, are closely linked and interact with each other. Therefore, the financing ecosystem can be considered as a complex ecosystem consisting of enterprises interacting with their competitors, complementary enterprises, and their environment in the form of capital flow, information flow, and energy flow. Financing niche is the position and function of an organism in financing ecosystem and its advantages and disadvantages in financing. It reflects not only the relationship between the organism and other organisms, but also the interaction between the organism and its environment.

Enterprises can only occupy a part of the financing ecological resources space in a certain period of time, that is, the financing niche of enterprises. Some foreign scholars believe that industrial policy is an external factor affecting the financing constraints and financing modes of emerging enterprises [1-3], while venture capital from the market is more able to distinguish the hidden value of emerging enterprises and provide more efficient financial support [4-6]. Therefore, the market-led financial system is more conducive to the growth of emerging industries with high R\&D density, high capital density, and high risks [7-9]. Chinese scholars pay attention to the important role of government behavior and macropolicies in the financing of emerging industries $[10,11]$. The key to the innovation growth of emerging enterprises is their industrial institutional environment. It is the key to cultivate the institutional environment of emerging industries to attach importance to the fundamental role 
TABLE 1: Financing niche evaluation index system.

\begin{tabular}{|c|c|c|}
\hline Niche & Index & Specific Explanation \\
\hline \multirow{4}{*}{ Market Financing Niche } & Economic Development Level & Per Capita GDP \\
\hline & Economic Financialization Degree & Total Financial Relevance Ratio \\
\hline & Contribution of Financial System & Ratio of Social Financing Scale to GDP \\
\hline & Social Financing Structure & Share Financing Ratio \\
\hline \multirow{4}{*}{ Industrial Financing Niche } & Industrial Growth Ability & Gross Industrial Output Growth Rate \\
\hline & Market Share & $\begin{array}{c}\text { Industrial Sales Output/National } \\
\text { Industrial Sales Output }\end{array}$ \\
\hline & R\&D Investment Degree & R\&D Input Cost/Gross Industrial Output \\
\hline & Financial Support & $\begin{array}{c}\text { Financial Investment/Gross Industrial } \\
\text { Output }\end{array}$ \\
\hline \multirow{9}{*}{$\begin{array}{l}\text { Enterprise's Financing } \\
\text { Niche }\end{array}$} & Short-term Liquidity & Liquidity Ratio \\
\hline & Long-term Solvency & Asset-liability Ratio \\
\hline & Growth Ability & Increase Rate of Business Revenue \\
\hline & Expansion Ability & Gross Asset Growth Rate \\
\hline & Operational Management Ability & Total Asset Turnover Rate \\
\hline & Earning Capacity & Net Interest Rate on Sales \\
\hline & Fund Investment in $\mathrm{R} \& \mathrm{D}$ & R\&D Expenses/Operating Revenue \\
\hline & Human Resources Investment in R\&D & $\begin{array}{c}\text { Number of Scientific Research } \\
\text { Technicians/Total Number of Employees }\end{array}$ \\
\hline & Financial Support & Government Subsidy/Operating Revenue \\
\hline
\end{tabular}

played by the market mechanism and maintain the balance between government and market forces.

Throughout the research results at home and abroad, there are many studies on the connotation, characteristics of financing ecology, the measurement of capital allocation efficiency, and its influencing factors [12-15], but few studies on the coevolution of financing niche and capital allocation efficiency. Therefore, this paper introduces the idea of niche and constructs financing ecosystem. Based on the improved Lotka-Volterra model [16], it studies the coevolution mechanism between financing niches and capital allocation efficiencies of emerging enterprises, which is conducive to revealing the deep-seated problems in the process of coordinated development of industrial capital allocation, and puts forward a new perspective on how to promote the coevolution of industrial capital allocation. It can also provide more profound theoretical interpretation and more sufficient empirical evidence for the relevant research of strategic emerging industries in China.

\section{Variable Design}

2.1. Financing Niche. The financing ecosystem is an ecosystem composed of the interaction of microlevel enterprise, industry mesolevel, and financing market macrolevel. The financing niche is the position, function, and role of an individual in the financing ecosystem, which is divided into an enterprise financing niche, industry financing niche, and market financing niche. Enterprise financing niche can be understood as a comprehensive level of resource ecology, technology ecology, and system ecology owned by enterprises in the process of capital financing. Industrial financing niche is a comprehensive level of industrial growth capacity, market share, industrial R\&D investment, and financial support. Market financing niche includes economic development level, economic level, the degree of financialization, the contribution of the financial system, and the structure of social financing.

According to relevant literatures [17, 18], a financing niche evaluation index system was constructed as Table 1 following the principles of systematisms, operability, effectiveness, and comparability.

Financing niche is composed of many indicators, which are generally realized by the integrated method of weighted summation. Projection pursuit model was first proposed by Friedman et al. in 1974 [19]. It is an effective method for exploratory data analysis to process and analyze highdimensional data. It is an effective method to avoid subjective interference of artificial empowerment and make the results more reasonable and realistic. It has been widely used in various fields of the comprehensive evaluation. Projection pursuit model was introduced to measure financing niche.

To eliminate the influence of different indicators on the results, the initial data are preprocessed, and the specific formula is shown as the following.

$$
x_{i j}= \begin{cases}\frac{x_{i j}^{0}-\min _{i}\left\{x_{i j}^{0}\right\}}{\max _{i}\left\{x_{i j}^{0}\right\}-\min _{i}\left\{x_{i j}^{0}\right\}}, & \text { income indicator } \\ \frac{\max _{i}\left\{x_{i j}^{0}\right\}-x_{i j}^{0}}{\max _{i}\left\{x_{i j}^{0}\right\}-\min _{i}\left\{x_{i j}^{0}\right\}}, & \text { cost indicator }\end{cases}
$$


In (1), $x_{i j}^{0}$ denotes the initial value of the $j^{\text {th }}$ indicator of the $i^{\text {th }}$ enterprise; $\max _{i}\left\{x_{i j}^{0}\right\}$ and $\min _{i}\left\{x_{i j}^{0}\right\}$ denote, respectively, the maximum and minimum values of the $j^{\text {th }}$ indicator; $x_{i j}$ denotes the standardized value of the $j^{\text {th }}$ indicator of the $i^{\text {th }}$ enterprise. The standardized data reflects the satisfaction degree of the index. The closer it approaches 1 , the more satisfied it is. The financing niche of the $i^{\text {th }}$ sample can be expressed as the following.

$$
Z_{i}=\sum_{j=1}^{p} a_{j} x_{i j} \quad(i=1,2, \cdots, n)
$$

In (2), $Z_{i}$ denotes the financing niche of the $i^{\text {th }}$ enterprise; $a_{j}\left(0 \leq a_{j} \leq 1\right)$ is the corresponding weight to the $j^{\text {th }}$ standardized indicator, which satisfies $\sum_{j=1}^{p} a_{j}^{2}=1 ; n$ is the number of enterprises; $p$ is the number of indicators. The optimal weight vector can be obtained by solving the following programming formulas:

$$
\begin{aligned}
& \max \quad Q(a) \\
& =\sum_{i=1}^{n} \sum_{k=1}^{n}\left(R-r_{i k}\right) f\left(R-r_{i k}\right) \\
& \cdot \sqrt{\frac{1}{n-1} \sum_{i=1}^{n}\left(Z_{i}-\frac{1}{n} \sum_{i=1}^{n} Z_{i}\right)^{2}} \\
& \text { s.t. } \quad \sum_{j=1}^{p} a_{i j}^{2}=1
\end{aligned}
$$

In (3), $Q(a)$ denotes the project function; $R$ denotes the radius of density-window width, which is usually given as $\alpha \sqrt{(1 /(n-1)) \sum_{i=1}^{n}\left(Z_{i}-(1 / n) \sum_{i=1}^{n} Z_{i}\right)^{2}}(0<\alpha<0.1) ; r_{i k}=$ $\left\|Z_{i}-Z_{k}\right\|(i, k=1,2, \cdots, n)$ denotes the distance between financing niches $Z_{i}$ and $Z_{k}$. It is required that the average number of projection points included in the window is not too small, and it will not increase too much with $n$. If $R \geq r_{i k}, f\left(R-r_{i k}\right)=1$; otherwise, $f\left(R-r_{i k}\right)=0$. It is obviously a nonlinear complex optimization problem. Simulated annealing algorithm was employed to solve this problem in the paper.

2.2. Capital Allocation Efficiency. The capital allocation efficiency of enterprises is to optimize and effectively allocate all kinds of funds raised by enterprises to produce the optimal product quantity combination and obtain the highest revenue. Domestic and foreign scholars mainly employed parameter estimation methods and nonparameter estimation methods to measure capital allocation efficiency. Data envelopment analysis is a nonparametric estimation method in efficiency measurement theory, which needs only relevant input-output indicators. According to the selection principle of input-output indicators, combined with cluster analysis and correlation analysis of initial financial indicators, the input-output indicators of capital allocation efficiency are finally determined reasonably and scientifically. According to the channels to raise funds for enterprises, the amount of endogenous financing, debt financing, and equity financing can be regarded as input indicators (sources of funds). Among them, the amount of endogenous financing is the sum of surplus reserve and undistributed profit, the amount of debt financing is the sum of short-term borrowing and longterm borrowing, and the amount of equity financing is the sum of paid-in capital (equity), capital reserve, and newly issued capital. Revenue and net profit are taken as output indicators.

Traditional DEA models cannot sort efficient decision making units. And capital allocation is a complex process, which cannot ignore the slacks of inputs and outputs. But traditional super-DEA models are radial. Therefore, based on the nonradial orientation of inputs in the process of capital allocation, the paper chooses the nonradial super-SBM DEA model to evaluate capital allocation efficiencies. To facilitate comparison, super-SBM DEA model is used to calculate capital allocation inefficiency of the enterprise by using the most possible improvement value of each input and output as denominator [20].This model solves the sorting problem among all the efficient units. The specific model is shown as the following.

$$
\begin{aligned}
\min \quad \theta & =\frac{(1 / m) \sum_{i=1}^{m} \bar{x}_{i} / x_{i o}}{(1 / s) \sum_{r=1}^{s} \bar{y}_{r} / y_{r o}} \\
\text { s.t. } \quad \bar{x} & \geq \sum_{j=1, j \neq o}^{n} \lambda_{j} x_{j} \\
\bar{y} & \leq \sum_{j=1, j \neq o}^{n} \lambda_{j} y_{j} \\
\bar{x} & \geq x_{o}=X \lambda+s^{-} \\
\bar{y} & \leq y_{o}=Y \lambda-s^{+} \\
\lambda_{j}, \bar{y} & \geq 0, i=1,2, \ldots, m ; r=1,2, \ldots, s ; j \\
& =1,2, \ldots, n .
\end{aligned}
$$

In (4), $\theta$ denotes the super-SBM efficiency score of the decision making unit with the input vector $x_{o} \in R^{m}$ and output vector $y_{o} \in R^{s}$. The slack vector $s^{-} \in R^{m}$ indicates the input excess. The slack vector $s^{+} \in R^{s}$ indicates the output shortfall. The input and output matrices are denoted as $X=\left(x_{1}, x_{2}, \cdots, x_{n}\right)=\left(x_{i j}\right)_{m \times n}$ and $Y=\left(y_{1}, y_{2}, \cdots, y_{n}\right)=$ $\left(y_{i j}\right)_{s \times n}$, respectively. $\lambda_{j}$ is a nonnegative number in $R$ and $\lambda \in R^{n}$ is the vector with the $j^{\text {th }}$ component $\lambda_{j} .(\bar{x}, \bar{y})$ is from the production probability set which spanned by $\left(x_{j}, y_{j}\right)(j=1,2, \cdots, n)$ excluding $\left(x_{o}, y_{o}\right) . m$ is the number of input indicators; $s$ is the number of output indicators; $n$ is the number of decision making units.

\section{Coevolutionary Model}

3.1. Financing Ecosystem. Similar to natural ecosystems, there are also coevolutionary relationships among enterprises, 


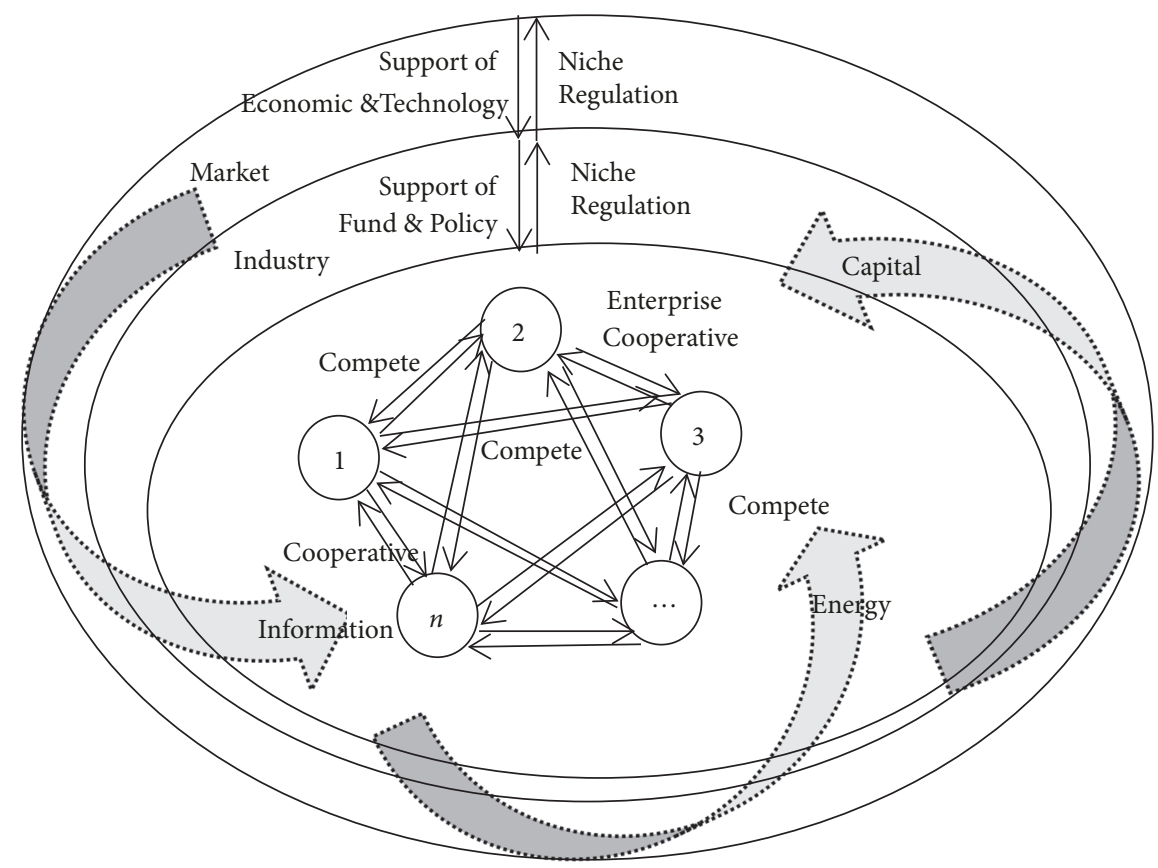

FIGURE 1: Financing ecosystem structure.

industries, and external financing environments in financing ecosystem. Financing ecosystem is a complex ecosystem involving three levels: microenterprise, medium-industry, and macrofinancing market. The microlevel of enterprises includes core enterprises, competitive enterprises, and complementary enterprises; the mesolevel of industry involves the environment of industrial development and policy support; and the macrolevel of financing market involves economic development, financial support, financing scale, and structure. The financing market of the strategic emerging industry is changing with time. The interaction between enterprises, industry, and market financing ecology in the financing process involves chaotic and complex interactions such as information flow, credit flow, and capital flow.

There are also competition, driving, guiding mechanism, and feedback mechanisms in the financing ecosystem. As the core mechanism in the financing ecosystem, competition mechanism determines the evolutionary path among enterprises, which is mainly manifested in natural selection, competition, and cooperation, as well as self-adaptive coordination. Driving mechanism is that the collection of driving forces formed by the gradual improvement of industrial development and financing market plays a role in the competition mechanism of the financing ecosystem and provides relevant feedback information. The guiding mechanism is provided by the government, enterprises, and market demand, directly determines the competitive environment of the financing ecosystem, and provides relevant feedback information. The feedback mechanism is responsible for liaising with the main bodies of the internal mechanism of the financing ecosystem, exchanging feedback information with competition, driving and guiding mechanisms, and producing positive and negative regulatory effects.
The interaction among four operation mechanisms in the financing ecosystem promotes the horizontal and vertical coupling and system integration of funds, information, and energy during enterprises, their industries, and external financing environment, then promotes the ecological allocation of enterprises' funds, and finally forms a stable financing ecosystem, as shown in Figure 1.

\subsection{Coevolution Model of Capital Allocation Efficiency and} Financing Niche. Lotka-Volterra model was proposed by American ecologist Lotka (1925) and Italian mathematician Volterra (1926), to describe the dynamic process of population size growth in the natural ecosystem when two species compete synergistically [16].

$$
\begin{aligned}
& \frac{d N_{1}}{d t}=r_{1} N_{1}\left(\frac{K_{1}-N_{1}-a_{12} N_{2}}{K_{1}}\right) \\
& \frac{d N_{2}}{d t}=r_{2} N_{2}\left(\frac{K_{2}-N_{2}-a_{21} N_{1}}{K_{2}}\right)
\end{aligned}
$$

In (5), $N_{1}$ and $N_{2}$ represent the populations of two species, respectively. $K$ and $r$ denote, respectively, the environmental capacity and growth rate of the species population. And both are greater than 0 , respectively, indicating the interaction effect of the two species. Both $a_{12}$ and $a_{21}$ are positive. The greater value means the stronger competition.

In recent years, Lotka-Volterra model has been widely applied in other fields, such as industrial system coupling association research [21], industrial cluster coevolution [22], and collaborative evolution process between competing enterprises [23]. However, most existing researches have 
discussed, respectively, the predatory competition relationship, the inhibition competition relationship, and the mutually beneficial symbiotic relationship between industrial or enterprise populations in Lotka-Volterra model, but these relationships often exist simultaneously in the ecosystem in reality, rather than being single or independent. Therefore, it is necessary to consider these relationships simultaneously in Lotka-Volterra model. In addition, enterprise's capital allocation is also affected by the coevolutionary dynamics of financing market pull, ecological pressure, industrial policy thrust, and enterprise endogenous financing drivers.

To this end, according to the financing ecosystem structure, enterprise's capital allocation efficiency, multilevel financing niche, and their coevolution are integrated into a unified research framework. Through optimizing and improving the improved Lotka-Volterra model, we constructed a coevolution model of capital allocation efficiency and financing niche for strategic emerging industries, as shown in (6).

$$
\begin{aligned}
z_{M}^{\prime} & =a_{M} z_{M}\left(1-b_{M} z_{M}+\eta_{M I} z_{I}+\sum_{i=1}^{n} \eta_{M E i} z_{E i}\right) \\
z_{I}^{\prime} & =a_{I} z_{I}\left(1-b_{I} z_{I}+\eta_{I M} z_{M}+\sum_{i=1}^{n} \eta_{I E i} z_{E i}\right) \\
z_{E_{1}}^{\prime} & =a_{E_{1}} z_{E_{1}}\left(1-b_{E_{1}} z_{E_{1}}+\eta_{E_{1} M} z_{M}+\eta_{E_{1} I} z_{I}\right. \\
& \left.+\sum_{i=2}^{n} \eta_{E_{1} E_{i}} z_{E_{i}}\right) \\
\ldots & \\
z_{E_{n}}^{\prime} & =a_{E_{n}} z_{E_{n}}\left(1-b_{E_{n}} z_{E_{n}}+\eta_{E_{n} M} z_{M}+\eta_{E_{n} I} z_{I}\right. \\
& \left.+\sum_{i=1}^{n-1} \eta_{E_{n} E_{i}} z_{E_{i}}\right) \\
\theta_{1}^{\prime} & =a_{1} \theta_{1}\left(1-b_{1} \theta_{1}+\eta_{\theta_{1} M} z_{M}+\eta_{\theta_{1} I} z_{I}+\eta_{\theta_{1} E_{1}} z_{E_{1}}\right) \\
\ldots & \\
\theta_{n}^{\prime} & =a_{n} \theta_{n}\left(1-b_{n} \theta_{n}+\eta_{\theta_{n} M} z_{M}+\eta_{\theta_{n} I} z_{I}+\eta_{\theta_{n} E_{n}} z_{E_{n}}\right)
\end{aligned}
$$

In (6), $M, I$, and $E_{i}$ denote, respectively, the market, industry, and the $i^{\text {th }}$ enterprise, and $z, \theta, a$ and $b$ denote, respectively, the financing niche, capital allocation efficiency, corresponding multiplication coefficients, and self-limiting parameter at time $t$. If $a>0$, the whole system is in an evolutionary state; if $a<0$, the whole system is in a degenerate state. $\eta_{i j}$ denotes the influence coefficient of financing niche $i$ on financing niche $j$. If $0<\eta_{i j}<1$ (or $\eta_{i j}>1$ ), it shows that the financing value of financing niche $i$ to financing niche $j$ is lower (or higher) than that of financing niche $j$ by itself. The greater the coefficient, the more obvious the synergistic effect. If $\eta_{i j}<0$, it shows that financing niche $i$ is not conducive to the promotion of financing niche $j$ and plays a restraining role. $n$ is the number of enterprises. If $\eta_{E_{i} E_{j}}>$ 0 and $\eta_{E_{j} E_{i}}>0$, there is a win-win relationship between enterprises $E_{i}$ and $E_{j}$. If $\eta_{E_{i} E_{j}}>0$ and $\eta_{E_{j} E_{i}}<0$, there is a win-win complementary competitive relationship between enterprises $E_{i}$ and $E_{j}$. If $\eta_{E_{i} E_{j}}<0$ and $\eta_{E_{j} E_{i}}<0$, there is a lose-lose competitive relationship between enterprises $E_{i}$ and $E_{j} \cdot \eta_{i}\left(i=M, I, E_{1}, \cdots, E_{5}\right)$ denotes the influence of financing niche occupied by market, industry, or enterprise on capital allocation efficiency. $\eta_{i j}<0$ shows that the financing niche plays a synergistic role. Otherwise, it plays a restraining role.

When the growth of financing niche and capital allocation efficiency reaches equilibrium, we have

$$
\begin{aligned}
& a_{M} z_{M}\left(1-b_{M} z_{M}+\eta_{M I} z_{I}+\sum_{i=1}^{n} \eta_{M E_{i}} z_{E_{i}}\right)=0 \\
& a_{I} z_{I}\left(1-b_{I} z_{I}+\eta_{I M} z_{M}+\sum_{i=1}^{n} \eta_{I E_{i}} z_{E_{i}}\right)=0 \\
& a_{E_{1}} z_{E_{1}}\left(1-b_{E_{1}} z_{E_{1}}+\eta_{E_{1} M} z_{M}+\eta_{E_{1} I} z_{I}+\sum_{i=2}^{n} \eta_{E_{1} E_{i}} z_{E_{i}}\right) \\
& \quad=0 \\
& \ldots \\
& a_{E_{n}} z_{E_{n}}\left(1-b_{E_{n}} z_{E_{n}}+\eta_{E_{n} M} z_{M}+\eta_{E_{n} I} z_{I}+\sum_{i=1}^{n-1} \eta_{E_{n} E_{i}} z_{E_{i}}\right) \\
& \quad=0 \\
& a_{1} \theta_{1}\left(1-b_{1} \theta_{1}+\eta_{\theta_{1} M} z_{M}+\eta_{\theta_{1} I} z_{I}+\eta_{\theta_{1} E_{1}} z_{E_{1}}\right)=0 \\
& \ldots \\
& a_{n} \theta_{n}\left(1-b_{n} \theta_{n}+\eta_{\theta_{n} M} z_{M}+\eta_{\theta_{n} I} z_{I}+\eta_{\theta_{n} E_{n}} z_{E_{n}}\right)=0
\end{aligned}
$$

We can obtain multiple equilibrium points of the coevolution model by solving (7). Only when market, industry, and enterprise financing niche and their capital allocation efficiency meet certain conditions, capital allocation efficiency and financing ecosystem of strategic emerging industries will evolve towards a stable structural state $\left(z_{M}^{e}, z_{I}^{e}, z_{E_{1}}^{e}, \cdots, z_{E_{n}}^{e}, \theta_{1}^{e}, \cdots, \theta_{n}^{e}\right)$ (equilibrium point).

3.3. Solving Parameters. It is often difficult to obtain satisfactory solutions for differential equations in coevolution models by using common parametric solving methods, and the maximum likelihood method needs to know the exact distribution of parameters in advance. An accelerated genetic algorithm has the characteristics of strong applicability, robust global optimization, less computation, and high accuracy. Therefore, the accelerated genetic algorithm was applied to estimate the parameters in the coevolution model. The specific model is shown as the following. 
$f_{1}$

$$
\begin{aligned}
& =\min \sum\left(\Delta z_{M}-a_{M} z_{M}(1\right. \\
& \left.\left.-b_{M} z_{M}+\eta_{M I} z_{I}+\sum_{i=1}^{n} \eta_{M E i} z_{E i}\right)\right)^{2}
\end{aligned}
$$

$f_{2}$

$$
\begin{aligned}
& =\min \sum\left(\Delta z_{I}-a_{I} z_{I}(1\right. \\
& \left.\left.-b_{I} z_{I}+\eta_{I M} z_{M}+\sum_{i=1}^{n} \eta_{I E i} z_{E i}\right)\right)^{2}
\end{aligned}
$$

$f_{3}$

$$
\begin{aligned}
& =\min \sum\left(\Delta z_{E 1}-a_{E_{1}} z_{E_{1}}(1\right. \\
& \left.\left.-b_{E_{1}} z_{E_{1}}+\eta_{E_{1} M} z_{M}+\eta_{E_{1} I} z_{I}+\sum_{i=2}^{n} \eta_{E_{1} E_{i}} z_{E_{i}}\right)\right)^{2} \\
& \text {... } \\
& f_{n+2} \\
& =\min \sum\left(\Delta z_{E n}-a_{E_{n}} z_{E_{n}}(1\right. \\
& \left.\left.-b_{E_{n}} z_{E_{n}}+\eta_{E_{n} M} z_{M}+\eta_{E_{n} I} z_{I}+\sum_{i=1}^{n-1} \eta_{E_{n} E_{i}} z_{E_{i}}\right)\right)^{2} \\
& f_{n+3} \\
& =\min \sum\left(\Delta \theta_{1}-a_{1} \theta_{1}(1\right. \\
& \left.\left.-b_{1} \theta_{1}+\eta_{\theta_{1} M} z_{M}+\eta_{\theta_{1}} z_{I}+\eta_{\theta_{1} E_{1}} z_{E_{1}}\right)\right)^{2} \\
& \text {... } \\
& f_{2 n+2} \\
& =\min \sum\left(\Delta \theta_{n}-a_{n} \theta_{n}(1\right. \\
& \left.\left.-b_{n} \theta_{n}+\eta_{\theta_{n} M} z_{M}+\eta_{\theta_{n}} z_{I}+\eta_{\theta_{n} E_{n}} z_{E_{n}}\right)\right)^{2}
\end{aligned}
$$

The initial ranges of parameters $a, b$, and $\eta$ are $[-2,2]$, $[-5,5]$, and $[-2,2]$, respectively. According to the optimization performance of the genetic algorithm operator, the variable change space of the excellent individuals generated by the first two evolutionary iterations is used as the new range. The algorithm enters the discretization and coding of the variable initial range, so as to accelerate the cycle until the optimization criterion function value of the optimal individuals is less than a certain set value or the algorithm runs to a predetermined number of accelerated cycles. The best individual in the population or an excellent individual is designated as the result of the accelerated genetic algorithm.

\section{Case Study}

4.1. Data Resource. In view of the availability of data, this paper chooses 2009-2017 as the research period and new energy vehicle listed companies as the initial sample. To validate the coevolution model, the top five new energy vehicle listed companies are selected as case sample. They are BYD company $\left(E_{1}\right)$, SAIC Group $\left(E_{2}\right)$, Chery Automobile Corporation Limited $\left(E_{3}\right)$, Anhui Jianghuai Automobile Corporation Limited $\left(E_{4}\right)$, and Jiangling Motors Corporation Limited $\left(E_{5}\right)$. All data related to enterprises are drawn from iFinD and CSMAR database. The data of industry and financing market are drawn from Industrial Statistics Yearbook, Economic Network Statistics Yearbook, Science and Technology Statistics Yearbook, and Statistics Yearbook in China from 2009 to 2017. Variables related to prices are reduced through the price index in 2009.

4.2. Results. According to the measures of financing niche and capital allocation efficiencies, the intermediate difference between market, industry, and enterprise financing niche and its capital allocation efficiencies is substituted into (8) of an accelerated genetic algorithm to obtain the estimated values $\widehat{a}, \widehat{b}$, and $\widehat{\eta}_{i j}$ of model parameters.

From Table 2, it is shown that the growth rate $\widehat{a}$ of each financing niche except for $E_{3}$ is greater than 0 , which indicates that the financing niches of market, industry, and these four enterprises have developed. Especially in recent years, the government has invested heavily in the new energy vehicle industry, continuously optimizing the financing environment. Besides, new energy vehicle enterprises have continuously improved their technical level. It is obviously known that market financing niche and industrial financing niche are a win-win relationship since $\hat{\eta}_{I M}>1$ and $0<\hat{\eta}_{M I}<1$. With the rapid development of new energy vehicle industry, the financing market is constantly improving, which shows the coevolutionary relationship. We can see $\widehat{\eta}_{E_{1} E_{2}}<-1$ and $\widehat{\eta}_{E_{3} E_{1}}<-1$ from Table 2. It shows that enterprises $E_{1}$ and $E_{2}$ are lose-lose relationship. The influence of competition between them is fierce. Under the limited financing resources, enterprises $E_{1}$ and $E_{2}$ compete with each other in the space of survival and development and eventually evolve toward a stable structure. $\widehat{\eta}_{E_{3} E_{1}}<-1$ and $-1<\widehat{\eta}_{E_{1} E_{3}}<$ 0 show that the competitiveness between financing niches of enterprises $E_{1}$ to $E_{3}$ is not equal. The competitiveness between financing niches of the enterprise $E_{1}$ to $E_{3}$ is intense, while the influence of financing niche of $E_{3}$ is weak to $E_{1}$, but it still belongs to a competitive coexistence relationship. $0<\widehat{\eta}_{E_{4} E_{1}}<1$ and $0<\widehat{\eta}_{E_{1} E_{4}}<1$ show that enterprises $E_{1}$ and $E_{4}$ are win-win relationship. The improvement to financing niches of enterprises $E_{1}$ and $E_{4}$ promotes each other and shows a mutually beneficial symbiotic relationship. $-1<$ $\widehat{\eta}_{E_{5} E_{2}}<0$ and $0<\widehat{\eta}_{E_{2} E_{5}}<1$ show that financing niches of enterprises $E_{2}$ and $E_{5}$ are win-win complementary competitive relationship. The improvement of financing niche of 
TABLE 2: Estimated value of parameters.

\begin{tabular}{lccccccccc}
\hline Variables & $\hat{a}$ & $\widehat{b}$ & $\hat{\eta}_{i M}$ & $\hat{\eta}_{i I}$ & $\hat{\eta}_{i E_{1}}$ & $\hat{\eta}_{i E_{2}}$ & $\hat{\eta}_{i E_{3}}$ & $\hat{\eta}_{i E_{4}}$ & $\hat{\eta}_{i E_{5}}$ \\
\hline$z_{M}$ & 0.0738 & 2.8564 & - & 0.7033 & 0.6396 & 0.4133 & -0.2263 & 0.2886 & -0.1789 \\
\hline$z_{I}$ & 0.1327 & 2.4702 & 1.0942 & - & 0.4635 & 0.2216 & 0.3301 & -0.3964 & 0.2653 \\
\hline$z_{E 1}$ & 0.1123 & 1.8237 & 0.5361 & 0.3224 & - & -1.1514 & -0.3117 & 0.2137 & 0.2271 \\
\hline$z_{E 2}$ & 0.0974 & 1.4343 & 0.4877 & 0.6622 & -1.1129 & - & 0.3326 & -0.5637 & 0.4497 \\
\hline$z_{E 3}$ & -0.0578 & -3.9844 & 0.5571 & 0.8374 & -1.1471 & -0.8183 & - & 1.0277 & 1.3166 \\
\hline$z_{E 4}$ & 0.0571 & 2.1839 & 1.0420 & 0.7443 & 0.5324 & -0.4151 & -0.6567 & - \\
\hline$z_{E 5}$ & 0.0728 & 2.5234 & 0.7321 & 0.5577 & 0.8777 & -0.6291 & -0.1717 & -0.5426 & - \\
\hline$\theta_{1}$ & 0.0924 & 1.7013 & -0.6468 & 0.3358 & 0.6652 & - & - & - \\
\hline$\theta_{2}$ & 0.0873 & 1.9164 & 0.4754 & 0.6763 & - & 0.7434 & - & - \\
\hline$\theta_{3}$ & 0.0938 & 1.7452 & 0.1429 & 0.2505 & - & - & 0.4211 & - \\
\hline$\theta_{4}$ & 0.0908 & 2.3954 & 0.2599 & 0.3211 & - & - & - & - \\
\hline$\theta_{5}$ & 0.0803 & 2.5753 & 0.6719 & 0.5268 & - & - & - & - \\
\hline
\end{tabular}
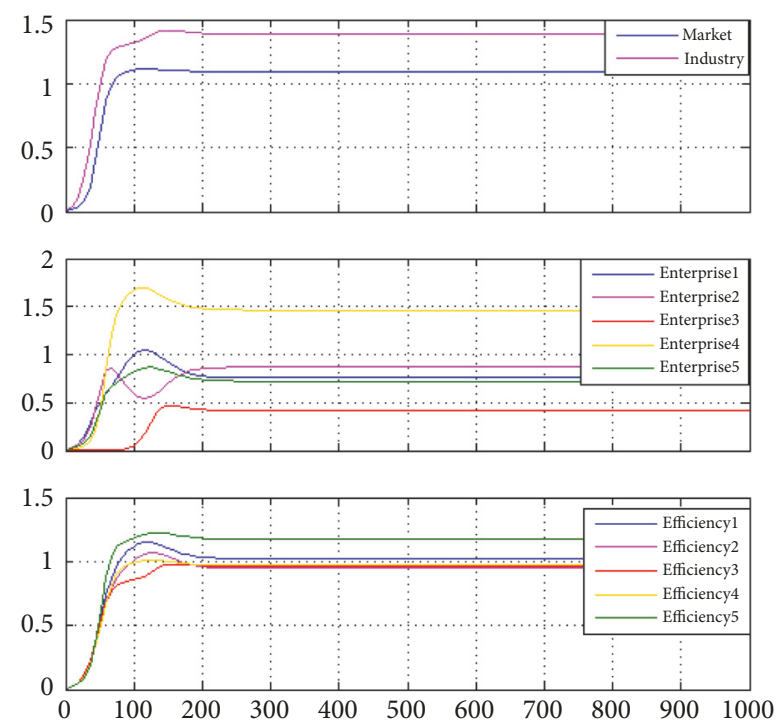

FIgURE 2: Coevolutionary chart of financing niche and capital allocation efficiency.

enterprise $E_{5}$ inhibits financing niche of enterprise $E_{2}$ and shows a competitive relationship, while financing niche of enterprise $E_{2}$ has a cooperative relationship with that of $E_{5}$. From $\eta_{\theta_{i} M}, \eta_{\theta_{i} I}, \eta_{\theta_{i} E_{i}}(i=1,2, \cdots, 5)$, the improvement of market, industry, and enterprise's financing niches except for enterprise $E_{1}$ will help to improve capital allocation efficiency. This is mainly because with the improvement of financing market and industrial policy, the competitive advantage of enterprise $E_{1}$ will gradually weaken, thus inhibiting its capital allocation efficiency.

Substituting these estimated values of parameters in Table 2 into (5), we can obtain the simulation diagram of the coevolution between financing niche and capital allocation efficiency, as shown in Figure 2. In Figure 2, the first figure is about market and industrial financing niches, the second figure is about enterprises' financing niches, and the last is about capital allocation efficiencies of all enterprises. The equilibrium points are, respectively, $z_{M}^{e}=1.0246, z_{I}^{e}=$
$0.9450, z_{E_{1}}^{e}=0.7571, z_{E_{2}}^{e}=0.8678, z_{E_{3}}^{e}=0.4133, z_{E_{5}}^{e}=$ $1.4642, \theta_{1}^{e}=1.0246, \theta_{2}^{e}=0.9450, \theta_{3}^{e}=0.9610, \theta_{4}^{e}=0.9714$, and $\theta_{5}^{e}=1.1731$. At this point, capital allocation efficiencies of $E_{1}$ and $E_{5}$ are efficient, and other companies have higher capital allocation efficiencies, greater than 0.94 .

Through simulation and comparative analysis, it is easily found that industrial financing niche first reaches a stable state, followed by market financing niche, and finally enterprise financing niches and then capital allocation efficiencies. The equilibrium point is mainly determined by the minimum of the breadths of market and industrial financing niches (the maximum of financing niche), which indicates that when the niche breadth of market or industry financing is small, the whole financing ecosystem will be in an inefficient coevolutionary equilibrium state. When the innovation of the market mechanism is continuously strengthened and the industrial policy is adjusted appropriately, new driving forces for development will be formed, thus evolving towards a new stable structure with the higher level.

\section{Conclusions}

By introducing the idea of niche, this paper designs the financing ecosystem and constructs a multilevel financing niche including financing market, industry, and enterprise. Based on the synergistic theory, the improved Lotka-Volterra model, the relationship among enterprises, industries, and their external financing markets is simultaneously incorporated into the proposed coevolution model of capital allocation efficiency and financing ecology of strategic emerging enterprises. The model reflects the synergistic competition coefficient among enterprises through different influence coefficients and explores and reveals the coevolution mechanism of multilevel financing niche and capital allocation efficiency. According to the data of five new energy vehicle listed companies in 2009-2017, we interpret and verify the linkage effect of the coevolution between financing ecology and capital allocation efficiency of emerging enterprises. The results show that the improvement of financing niche in financing market will help to promote financing niches of 
industry and enterprise. And the improvement of industrial financing niche will also contribute to financing niches of financing market and enterprises. The financing market has the greatest impact on the industrial financing niche. The improvement of financing niches of market, industry, and enterprises will help to promote capital allocation efficiencies of enterprises. There exist competition and cooperation among the five enterprises. Each financing niche and capital allocation efficiency will eventually evolve toward a stable equilibrium point. The equilibrium point of the coevolutionary model depends on the minimum of the financing niche breadth of financing market and industry.

According to the ecological evolutionary characteristics reflected in the coevolutionary process of financing ecology and capital allocation efficiency of strategic emerging enterprises, the following countermeasures are proposed. Firstly, enterprises should cultivate their own niche by practicing internal strength and optimize endogenous financial communication capacity and capital allocation efficiency through dynamic evolutionary regulation of niche in financing ecosystem. Secondly, the government should formulate effectively industrial policies, optimize the financing market and industrial financing niche, shore up weak spots of financing niche, give play to the decisive role of market in resource allocation, and coordinate the synergistic evolution direction of the whole system.

Finally, combining with the dynamic adjustment effect on financing niches of strategic emerging enterprises, we should take enterprise development as the core and financing ecosystem optimization as support. And we should enhance the synergetic coevolution driven by capital dynamics, market pull, government thrust, and ecological pressure, in order to achieve a dynamic equilibrium of the operation of entire financing ecosystem, and advance the coevolution between capital allocation efficiency and financing ecology, and promote the healthy and sustainable development of strategic emerging industries.

\section{Data Availability}

All data of enterprises are drawn from iFinD and CSMAR database. The data related to industry and financing market are drawn from Industrial Statistics Yearbook, Economic Network Statistics Yearbook, Science and Technology Statistics Yearbook, and Statistics Yearbook in China from 2009 to 2017. Variables related to prices are reduced through the price index in 2009.

\section{Conflicts of Interest}

The authors declare that there are no conflicts of interest regarding the publication of the paper.

\section{Authors' Contributions}

Qiong Wang and Cheng-xuan Geng conceived the experiments. Qiong Wang performed the experiments and analyzed the data. Qiong Wang, Cheng-xuan Geng, and Hai-tao E wrote the paper together.

\section{Acknowledgments}

This research is supported by National Social Science Foundation of China (15BGL056) and Fundamental Research Funds for Central Universities (NW2019002). Moreover, we are grateful for the anonymous referees for their careful evaluation and critical comments, which greatly improved the quality of this paper.

\section{References}

[1] J. Madura and W. Reiff, "A hedge strategy for international portfolios," The Journal of Portfolio Management, vol. 12, no. 1, pp. 70-74, 1985.

[2] M. G. Colombo and L. Grilli, "Funding gaps? Access to bank loans by high-tech start-ups," Small Business Economics, vol. 29, no. 1-2, pp. 25-46, 2007.

[3] M. Nishihara and T. Shibata, "Interactions between preemptive competition and a financing constraint," Journal of Economics \& Management Strategy, vol. 19, no. 4, pp. 1013-1042, 2010.

[4] L. K. C. Chan, "Uncertainty and the neutrality of government financing policy," Journal of Monetary Economics, vol. 11, no. 3, pp. 351-372, 1983.

[5] R. Amit, J. Brander, and C. Zott, "Why do venture capital firms exist? theory and canadian evidence," Journal of Business Venturing, vol. 13, no. 6, pp. 441-466, 1998.

[6] G. Avnimelech and M. Teubal, "Creating venture capital industries that co-evolve with high tech: Insights from an extended industry life cycle perspective of the Israeli experience," Research Policy, vol. 35, no. 10, pp. 1477-1498, 2006.

[7] R. Fisman and I. Love, "Trade credit, financial intermediary development and industry growth," Journal of Finance, vol. 58, no. 1, pp. 353-374, 2003.

[8] J. R. Brown, S. M. Fazzari, and B. C. Petersen, "Financing innovation and growth: Cash flow, external equity, and the 1990s r\&d boom," Journal of Finance, vol. 64, no. 1, pp. 151-185, 2009.

[9] J. Bena and P. Ondko, "Financial development and the allocation of external finance," Journal of Empirical Finance, vol. 19, no. 1, pp. 1-25, 2012.

[10] Z. Yihe, "A study of the strategies in government support of new industries venture capital," Journal of Hubei University of Technology, vol. 6, pp. 58-60, 2010.

[11] Li. Zhaohui, "Countermeasures and suggestions on establishing venture capital guidance fund for national strategic emerging industries," in Modern Economic Research, vol. 10, pp. 39-43, 3943, 10, 2011.

[12] S. Wei, "Design and optimization of an evaluation index for science and technology investment and financing ecosystem," Science \& Technology Progress and Policy, vol. 26, no. 22, pp. 140143, 2009.

[13] S. Tong, H. Lu, and Q. Qingzhu, "Assessment of financing environment of the domestic cultural industry," Statistics \& Decision, vol. 12, pp. 49-52, 2012.

[14] Y. Yaojun and H. Lindong, "Does the improvement of financial ecological environment help to improve capital allocation efficiency?-empirical evidence from zhejiang province," Financial Theory and Practice, vol. 2, pp. 41-44, 2012. 
[15] G. Chengxuan, L. Meng, and E. Haitao, "Financing ecology and financing constraints of new energy enterprisesan empirical analysis of Chinese A-share new energy listed companies," East China Economic Management, vol. 32, no. 1, pp. 153-159, 2018.

[16] S.-Y. Chiang, "An application of Lotka-Volterra model to Taiwan's transition from $200 \mathrm{~mm}$ to $300 \mathrm{~mm}$ silicon wafers," Technological Forecasting \& Social Change, vol. 79, no. 2, pp. 383-392, 2012.

[17] H. Du, Q. Xia, X. Ma, and L. Chai, "A new statistical dynamic analysis of ecological niches for China's financial centres," Physica A: Statistical Mechanics and its Applications, vol. 395, pp. 476-486, 2014

[18] W. Qiong and G. Cheng-Xuan, "Research on financing efficiencies of strategic emerging listed companies by six-stage dea model," Mathematical Problems in Engineering, vol. 2017, Article ID 3284657, 8 pages, 2017.

[19] J. H. Friedman and J. W. Tukey, "A projection pursuit algorithm for exploratory data analysis," IEEE Transactions on Computers, vol. 23, pp. 881-890, 1974.

[20] K. Tone, "A slacks-based measure of super-efficiency in data envelopment analysis," European Journal of Operational Research, vol. 143, no. 1, pp. 32-41, 2002.

[21] Z. Tiantian and W. Wenping, "Study on coordination of provincial industrial eco-economic system based on lotka-volterra," Chinese Journal of Management Science, vol. 22, pp. 240-246, 2014.

[22] L. Yue, "Research on co-evolution emerging industry clusters based on niche adjust," Science \& Technology Progress and Policy, vol. 35, no. 3, pp. 52-59, 2018.

[23] H. Wangen, S. Yaowu, and Bing. H., "Modeling and simulation of niche evolution and coopetition between enterprises-a case study in telecom operators and mobile ott providers," Journal of Industrial Technological Economics, vol. 3, pp. 153-160, 2015. 


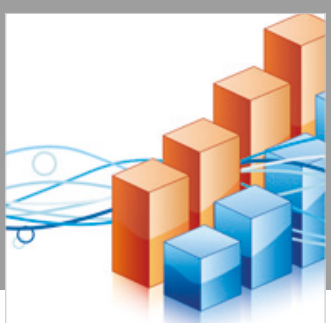

Advances in

Operations Research

\section{-n-m}
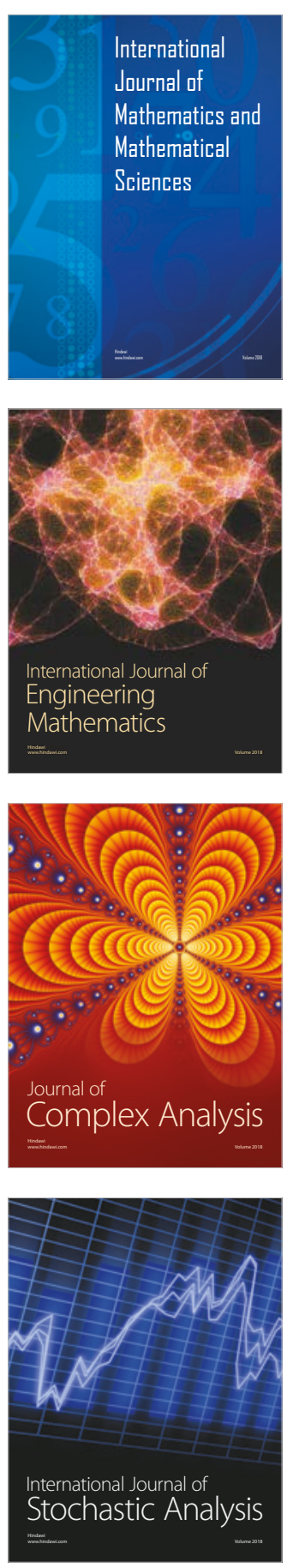
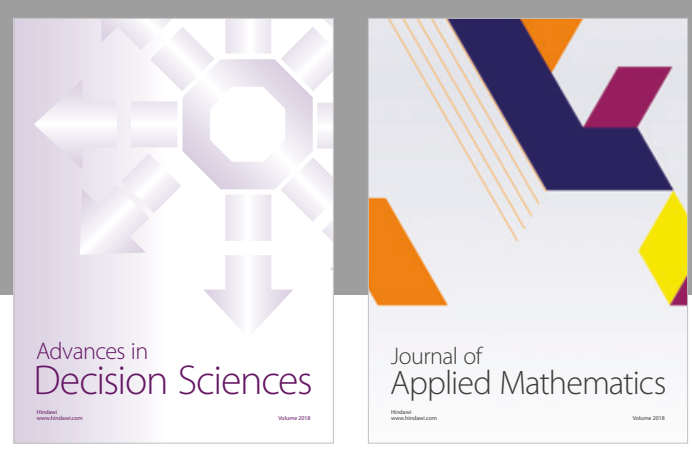

Journal of

Applied Mathematics
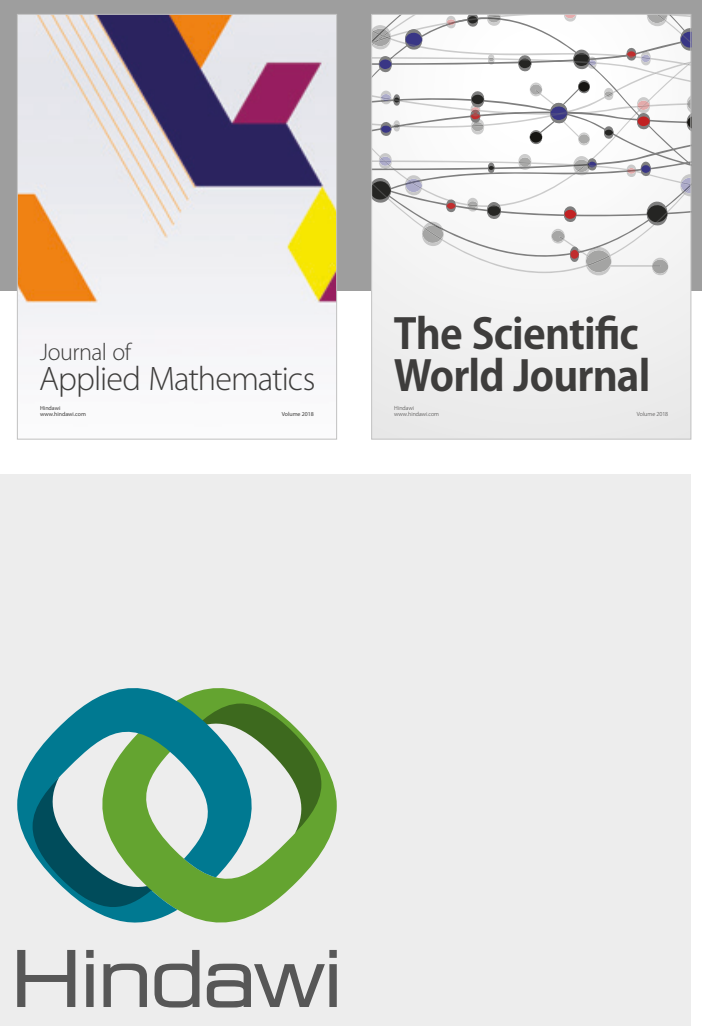

Submit your manuscripts at

www.hindawi.com

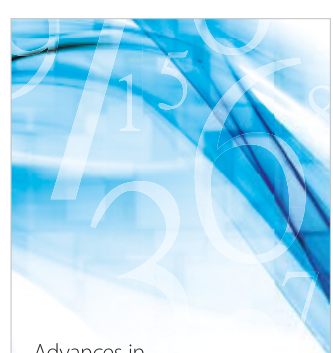

Advances in
Numerical Analysis
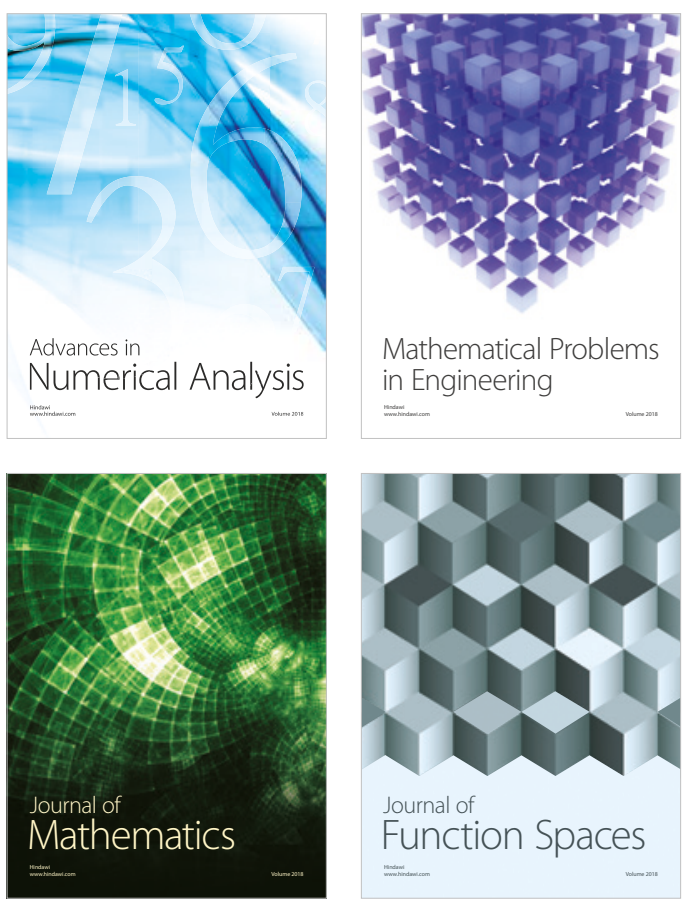

Mathematical Problems in Engineering

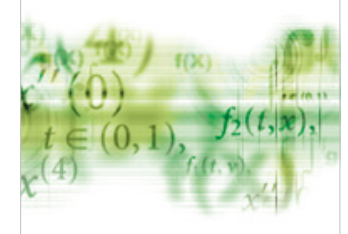

International Journal of

Differential Equations

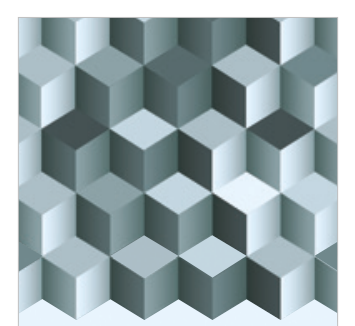

Journal of

Function Spaces

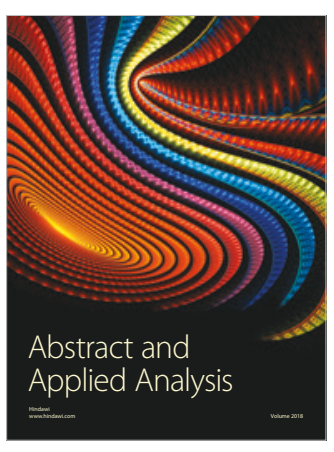

The Scientific

World Journal

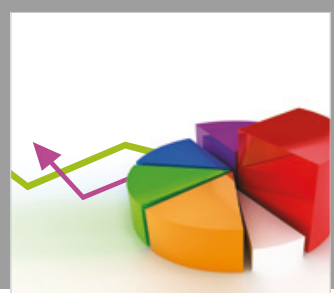

Journal of

Probability and Statistics
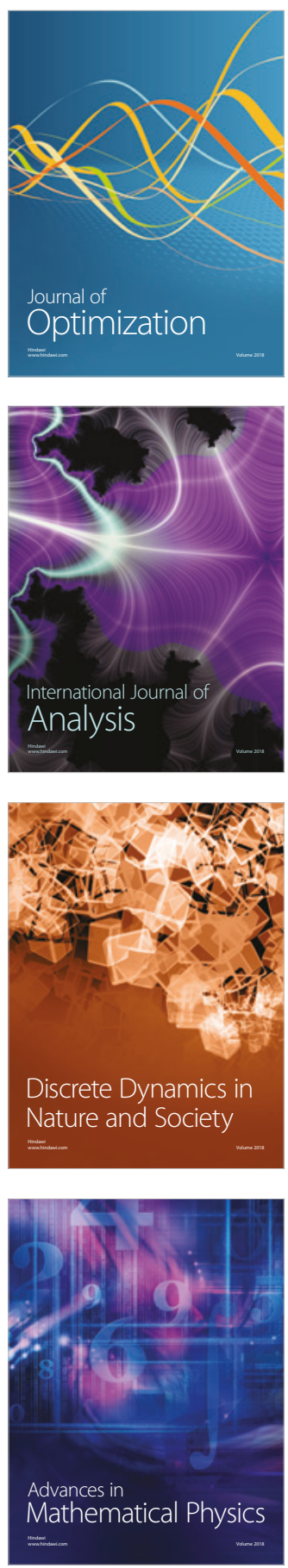